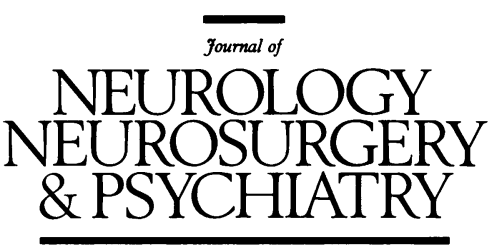

\title{
Editorial
}

\section{A pathophysiological approach to saccadic eye movements in neurological and psychiatric disease}

Normal vision represents a complex sensorimotor act in which eye movements provide two essential components. One is the ability to shift gaze rapidly to bring the image of an object of interest on to regions of the retina containing the highest density of photoreceptors, the fovea, and the other is to stabilise the new image on this area despite movement of the object (smooth pursuit) or of the head and body (vestibulo-ocular and optokinetic reflexes). It is the rapid gaze shifts, saccades, which enable mammalian predators to identify possible prey in the visual scene, in response to the sudden appearance of its image on the peripheral retina. These saccades are termed reflexive because they are made in response to the appearance of a novel visual target in the peripheral visual field (visually guided reflexive saccade), or to an auditory stimulus (auditory reflexive saccade). Intentional (voluntary) saccades are internally triggered, and are made to foveate a goal in a variety of different circumstances. In a visual search mode a series of saccades (the scanpath) may be made to locate a target of interest in the environment or to identify an object. If this target of interest is expected at a known location a predictive saccade may be generated, or, if it has previously been present but then disappears, a memory guided (remembered) saccade will be made. In addition to these ecologically valid situations are other paradigms such as the antisaccade task which will be discussed later, devised by experimenters to test aspects of the functional integrity of the saccadic neural circuitry. All these saccades are internally generated, along with the spontaneous saccades which occur at rest or during other activities such as speech.

\section{Brainstem control of saccades}

The final common pathway for horizontal saccades is the abducens nucleus which contains motor neurons innervating the ipsilateral lateral rectus muscle, intermingled with internuclear neurons which, after decussating in the lower pons, project via the medial longitudinal fasciculus to the contralateral medial rectus subnucleus of the oculomotor nucleus. ${ }^{1}$ A total ipsilateral gaze palsy occurs with a lesion of the abducens nucleus, and a complete lesion of the medial longitudinal fasciculus gives rise to total failure of ipsilateral adduction associated with nystagmus in the abducting eye, an internuclear ophthalmoplegia. ${ }^{2}$ The saccadic motor command received in the abducens nucleus is prepared in specialised areas of the reticular formation of the brainstem, which receive supranuclear inputs from a number of different areas. The main premotor region for horizontal saccades is the paramedian pontine reticular formation, located on either side of the midline in the nuclei reticularis pontis just ventral to and extending rostrally from the abducens nucleus $^{3}$ (figure). The equivalent premotor area for vertical saccades is the rostral interstitial nucleus of the medial longitudinal fasciculus located rostral to the oculomotor nucleus at the level of the upper pole of the red nucleus. ${ }^{5}$ The paramedian pontine reticular formation of the rostral interstitial medial longitudinal fasciculus nucleus contain various groups of cells with different functions and properties. These include the excitatory burst neurons which discharge at a high frequency just before and during saccades, ${ }^{6}$ providing the eye velocity commands, known as the "pulse". Discrete lesions of the paramedian pontine reticular formation only produce a loss of saccades and quick phases of nystagmus to the side ipsilateral to the lesion, ${ }^{7}$ whereas a lesion of the abducens nucleus results in a complete ipsilateral gaze palsy, involving all types of eye movement. ${ }^{8}$ Another type of neuron, the omnipause neuron, located in a midline caudal pontine area, the nucleus raphe interpositus, discharges tonically except just before and during saccades. ${ }^{9}$ These neurons appear to exert an inhibitory influence on the burst neurons during fixation, and slowed saccades may result from omnipause cell dysfunction in some conditions. ${ }^{10}$

Following a laterally directed saccade, viscoelastic forces in the orbit tend to drag the eye back to the primary position. Maintenance of the eccentric position of the eye, therefore, requires tonic change in the innervation level of the abducens motor neurons, called the "step". This is provided by a third set of neurons known as integrator neurons because they produce the equivalent of a mathematical integration of the burst neuron activity. The integrator neurons are located in the perihypoglossal complex (especially the nucleus prepositus hypoglossi) and the medial vestibular nuclei. ${ }^{11}$ Dysfunction of the integrator neurons or their inputs, particularly from the flocculus, results in an exponential drift of the eye towards the primary position due to a poorly maintained step innervation. ${ }^{12}$ A saccade (fast phase) returns the eye to refixate the target, resulting in the development of gaze evoked nystagmus. Disturbances of saccades, therefore, can be considered in terms of the pulse-step innervation pattern of the motor neuron, 


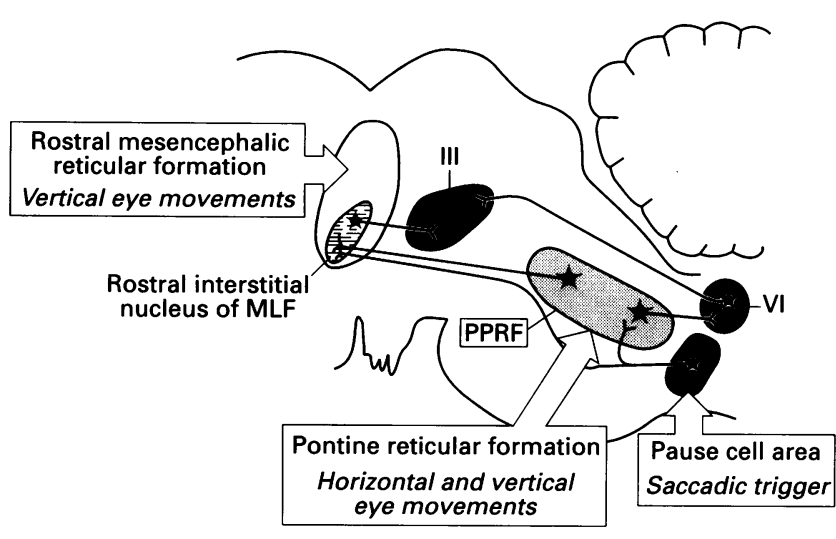

A schematic diagram of the brainstem to show the location of the main centres and connections involved in the generation of horizontal and vertical components of saccades. (From Büttner-Ennever ${ }^{4}$ with permission.)

determined by the functional integrity of the burst, integrator and omnipause cells and their inputs.

The cerebellum, as well as influencing the saccadic integrator, is involved in calibrating the size of the saccadic pulse. Lesions of the dorsal vermis and the underlying fastigial nucleus give rise to disorders of saccadic amplitude, usually hypermetria (abnormally large saccade), which may be most obvious in centripetal saccades. ${ }^{13}$ Hypermetria can also be observed in brainstem lesions, such as Wallenberg's syndrome. ${ }^{14}$

An important brainstem centre involved in triggering saccades is the superior colliculus, which appears to be an important relay between cortical areas and the premotor reticular regions. Only two patients with discrete lesions of the superior colliculus have been reported, and they were found to have impairment of both the triggering and the inhibition of contralaterally directed reflexive saccades. ${ }^{1516}$

\section{Saccadic intrusions and oscillations}

Although the main function of saccades is to achieve foveation of the target there are several conditions in which saccades take the fovea off the target. These may be sporadic and biphasic, termed intrusions, or sustained sequences of saccades, termed oscillations. They must be distinguished from nystagmus in which the oscillation is initiated by a smooth eye movement. These involuntary saccades occur in brainstem, cerebellar, and cerebral disease.

The commonest intrusions are square wave jerks which occur during fixation and conjugately displace the eyes $0 \cdot 5-10^{\circ}$ horizontally, followed after approximately $200 \mathrm{~ms}$ by a refixation saccade. They occur in normal subjects at a frequency usually less than 15 per minute and $1-2^{\circ}$ in amplitude. ${ }^{17}$ Abnormally high frequencies of square wave jerks are found in normal elderly subjects, in cerebellar system disease, ${ }^{18}$ and certain types of parkinsonism such as progressive supranuclear palsy and multiple system atrophy. ${ }^{19}$ A saccadic pulse is a saccade, generated by a burst (pulse) of motor neuron innervation, which is not followed by a step, and is therefore followed by a slow phase drift of the eye back to the fixation position. They may be monocular or binocular and occur most commonly in patients with multiple sclerosis. ${ }^{20}$ Anticipatory saccades are large amplitude saccades which take the eye away from the fixated target and are followed after several hundred milliseconds by a refixation saccade. They are characteristically seen in senile dementia of Alzheimer's type ${ }^{21}$ and Huntington's disease. ${ }^{22}$
Saccadic oscillations can be considered repetitive bursts of intrusions and may be distinguished by the presence or absence of an intersaccadic interval, which usually has to be determined by oculographic recordings. Macrosaccadic oscillations are horizontal salvos of saccades which straddle the intended fixation point with an intersaccadic interval of about $200 \mathrm{~ms}$. They are mainly associated with cerebellar lesions especially of the deep cerebellar nuclei. ${ }^{23}$ Opsoclonus and ocular flutter consist of back to back saccades, that is, no intersaccade interval, which are multidirectional in the former, and only horizontal in the latter. Although it has been hypothesised that dysfunction of the omnipause neurons may produce opsoclonus, ${ }^{24}$ pathological examination of the nucleus raphe interpositus in patients with opsoclonus failed to reveal any abnormalities. ${ }^{25}$ Instead opsoclonus may result from abnormal inputs to either the burst or pause neurons. Opsoclonus most frequently occurs in relation to a viral encephalitis or as a paraneoplastic manifestation in children usually due to an occult neuroblastoma, or in adults due to a carcinoma of the lung, breast, or uterus. ${ }^{26}$

\section{Cortical control of saccades}

There are two main areas of the cerebral cortex involved in triggering saccades. The frontal eye field which lies at the caudal end of the middle frontal gyrus (Brodmann's area 8) and adjacent precentral gyrus, and the posterior parietal cortex in the region of the superior part of the angular gyrus (Brodmann's area 39). Two other areas have been identified as being involved in saccade generation; the supplementary motor area which lies medially in the first frontal gyrus (Brodmann's area 6), and the dorsolateral prefrontal cortex (Brodmann's area 46). Although the generation of saccades by the cortex is still incompletely understood, there is converging evidence from animal neurophysiology, and human lesion and neuroimaging studies that enable us to describe the relative roles of these different areas, along with the basal ganglia. This provides a useful basis on which to consider the effect on saccades of a number of different neurological and psychiatric diseases.

It has been known for over a century that electrical stimulation of the frontal eye field in the monkey results in a contralaterally directed saccade, ${ }^{27}$ whereas an acute lesion due to infarction in man produces a failure of such saccades. This is often associated with an ipsilaterally directed conjugate deviation of the eyes which is usually only temporary, ${ }^{28}$ unless there is preexisting damage to the contralateral frontal eye field. ${ }^{29}$ Thereafter contralateral reflexive saccades are usually normal or of slightly prolonged latency, ${ }^{30}$ despite neurophysiological evidence for involvement of frontal eye field cells in all types of saccades. ${ }^{31}$ Memory guided saccades made to the remembered location of a previously visible target located either contralaterally or ipsilaterally to the lesion show a prolonged latency and reduced accuracy. ${ }^{32}$ This suggests that each frontal eye field can control saccades directed bilaterally, and is the probable explanation for the relatively subtle saccadic abnormalities which are found following unilateral lesions.

The supplementary motor area is generally considered to be involved in the preparation and coordination of somatomotor programmes. Recent neurophysiological recordings in monkeys have identified an area in the rostral supplementary motor area containing cells which discharge in relation to saccades, called the supplementary eye field. ${ }^{33}$ Focal unilateral lesions of the supplementary motor area in man have failed to reveal abnormalities in visually directed reflexive saccades, single memory 
guided saccades or antisaccades, ${ }^{30} 32$ although recent activation studies using PET have shown significant activation of the supplementary motor area in the last two paradigms. ${ }^{34} 35$ Lesions of the supplementary motor area, however, result in saccadic abnormalities when sequences of memory guided saccades ${ }^{36}$ or memory guided saccades made after a body rotation (i.e. based on vestibular input $)^{37}$ were performed.

An important role for the frontal lobes is that of inhibiting routine or automatic behaviour when it is irrelevant to the current action plan, failure of which leads to distractibility and indecisiveness. A good challenge to this system is the antisaccade paradigm in which the subject is instructed to suppress a reflexive saccade on the appearance of a peripheral target, while at the same time generating a voluntary saccade to a mirror image location in the contralateral visual field. Increased distractibility (an abnormally high frequency of reflexive saccades) was initially found in patients with large frontal lobe lesions, ${ }^{38}$ that appears to relate more specifically to focal lesions in the region of the dorsolateral prefrontal cortex. ${ }^{30}$ These observations, along with PET studies which have shown activation of prefrontal cortex during fixation, ${ }^{34}$ suggest that this cortical area may be involved in the inhibition of reflexive saccades. The pathways from these cortical areas to the brainstem have not been clearly identified, but could project to fixation cells in the superior colliculus or omnipause neurons in the nucleus raphe interpositus. Two routes to the superior colliculus are available, one direct ${ }^{39}$ and the other via the caudate nucleus and the substantia nigra pars reticulata which tonically inhibits the superior colliculus. ${ }^{40}$

The dorsolateral prefrontal cortex has also been considered to play a role in short term spatial memory since this area contains cells which discharge during the delay period in the memory guided saccade paradigm, ${ }^{41}$ and lesions and blockade of D1 dopamine receptors in the area result in hypometric memory guided saccades. ${ }^{42}$

The posterior parietal cortex has direct connections with the frontal eye field and the superior colliculus, the latter providing a probable route for saccade generation following lesions of the frontal eye field. Unilateral lesions of the posterior parietal cortex result in increased latencies of visually directed reflexive saccades ${ }^{43}$ and decreased accuracy of memory guided saccades. ${ }^{32}$ The latter may be due to impaired visuospatial integration in the human homologue of area $7 \mathrm{a}$ in the monkey. ${ }^{44}$ Following right parietal lesions the effects are more marked and affect saccades bilaterally, supporting the concept of the dominance of the right parietal lobe for visuospatial functions in humans. It should be noted that there is no correlation between visual neglect and these saccadic disturbances following a lesion in the posterior parietal cortex, presumably due to a separation of the areas involved in the control of saccades and visual attention.

\section{Disorders of the basal ganglia}

A wide variety of saccadic abnormalities have been associated with diseases of the basal ganglia. In Huntington's disease, where there is degeneration in the caudate nucleus and substantia nigra pars reticulata as well as the frontal lobes, a number of saccadic abnormalities have been identified including difficulty in suppressing reflexive saccades in the antisaccade task, ${ }^{45}$ and prolonged latencies of memory guided and predictive saccades. ${ }^{46}$ In addition, during fixation there are increased numbers of square wave jerks, and a slowing of saccadic velocity which usually affects vertical saccades prior to involvement of horizontal saccades. ${ }^{47}$
Because of the difficulties often encountered in the differential diagnosis of parkinsonian syndromes a number of saccadic studies have recently been reported aimed at identifing specific patterns of saccadic abnormalities in the different conditions. ${ }^{48-51}$ In idiopathic Parkinson's disease reflexive saccades are normal ${ }^{49}$ except in the very late stages of the disease..$^{50}$ Patients, however, exhibit a reduction in the amplitude of memory guided ${ }^{49}$ and predictive saccades. ${ }^{52}$ In progressive supranuclear palsy there is often an early reduction in the velocity of downward and later upward saccades leading to a complete supranuclear palsy in which the vestibulo-ocular reflex is usually preserved. ${ }^{53}$ These saccadic abnormalities are probably a reflection of the focus of degenerative change in this condition involving midbrain structures such as the superior colliculus, rostral interstitial nucleus of the medial longitudinal fasciculus, as well as the substantia nigra pars compacta. In addition there is also increased distractibility in the antisaccade task, ${ }^{54}$ which may be due to a functional deafferentiation of the prefrontal cortex from the subcortical areas. Vertical saccades are preserved in other parkinsonian syndromes such as strionigral degeneration and corticobasal degeneration. Saccades in striatonigral degeneration could not be differentiated from those in idiopathic Parkinson's disease, whereas in corticobasal degeneration, visually guided reflexive saccades showed markedly prolongated latencies, ${ }^{51}$ possibly reflecting degeneration in the parietal lobes.

\section{Saccadic abnormalities in functional psychoses}

The literature on eye movements in the psychoses has centred on the analysis of smooth pursuit eye movements in schizophrenia, ${ }^{55}$ with the specific intent of identifying an abnormality which could serve as a biological marker for the disorder. Although it was 1908 when Diefendorf and Dodge first reported an analysis of saccades in schizophrenia, ${ }^{56}$ it is only recently that there has been renewed interest. A major methodological problem, however, has been the almost universal use of patients treated with neuroleptic medication, which raises doubts about the validity of conclusions relating abnormalities of saccadic latency and amplitude to the underlying disease process. One of the most obvious side effects of neuroleptic medication is an extrapyramidal syndrome due to blockade of the nigrostriatal dopamine pathway, and from the discussion of saccadic abnormalities in Parkinson's disease it might be expected that some if not all the saccadic abnormalities found in neuroleptically treated schizophrenic patients could be due to this effect. In a recent study this potential drug effect has been clarified by a comparison of groups of patients free from neuroleptic medication with other groups of patients taking medication. ${ }^{57}$ In the memory guided and predictive saccadic tasks a reduced saccadic amplitude, as previously reported in Parkinson's disease, was only found in the neuroleptic treated groups. In obsessive compulsive disorder, there is an abnormal tendency towards hypometria, which is most marked for predictive saccades, ${ }^{58}$ consistent with the idea that those frontobasal ganglia pathways that are hypoactive in negative schizophrenia are hyperactive in obsessive compulsive disorder. ${ }^{59}$

One saccadic abnormality found in schizophrenia which was unrelated to neuroleptic medication does, however, appear to relate to the underlying disease pathology. This is an increased distractibility in the antisaccade task, ${ }^{60}$ as found in neurological patients with lesions in the prefrontal cortex. Several recent studies have shown this abnormality which was most marked in patients exhibiting tardive dyskinesia, ${ }^{61}$ frontal atrophy, ${ }^{62}$ 
and either perseverative errors in the Wisconsin card sort test or an abundance of negative signs, ${ }^{57}$ both of which are associated with frontal lobe dysfunction. These findings, therefore, suggest that the saccadic distractibility found in schizophrenia represents some general frontal type dysfunction of strategic control processes in schizophrenia. ${ }^{63}$ In line with the view that underlying schizophrenic negative symptoms lies a disorder of uncued, internally generated action, ${ }^{63}$ the saccades employed in spontaneous scanning of visual patterns also seem to be abnormal in negative schizophrenia. ${ }^{64}$ Prefrontal regions seem to play a role in the control of these saccades. ${ }^{65}$

\section{Conclusions}

From this brief survey of saccadic disorders it is apparent that analysis of saccadic function can be of value in clinical practice to assist in the differential diagnosis and anatomical localisation of a wide variety of diseases. Although oculographic recordings are required in some situations simple clinical observation will often suffice. This should include careful inspection for saccadic intrusions and oscillations during fixation, and of horizontal and vertical saccades generated at the bedside reflexively in response, for example, to the brief flash of a torch or sudden movement of a finger, and volitionally to a spoken command. In addition, saccades can be used to serve as a model system for the analysis of the neural control of motor performance. In the future, the continuing interaction between clinicians and neurophysiologists will help to refine more precisely the role of the many different neural centres in saccade generation, a task which will be increasingly aided by the use of functional imaging with PET. ${ }^{34366}$ One area of study which has received little attention is the neuropharmacology of saccades. ${ }^{67}$ Initial studies, for example, correlating saccadic function with the pharmacokinetics of benzodiazepines, ${ }^{68}$ or analysing the effects of neuroleptic drugs in schizophrenia ${ }^{57}$ or of catecholamine depletion, ${ }^{69}$ suggest that this could prove to be of considerable interest.

C KENNARD, T J CRAWFORD,

Academic Unit of Neuroscience, L HENDERSON

Charing Cross and Westminister Medical School,

St Dunstans Road, London W6 8RF, UK

Correspondence to: Professor C Kennard.

1 Leigh RJ, Zee DS. The neurology of eye movements, 2nd edn. Philadelphia, PA: Davis, 1991.

2 Büttner U, Brandt $T$, eds. Ocular motor disorders of the brain stem. Bailliere's clinical neurology, 1992:1

3 Büttner-Ennever JA, Büttner U. The reticular formation. In: BüttnerEnnever JA, ed. Neuroanatomy of the oculomotor system. Amsterdam: Elsevier, 1988:119-76.

4 Büttner-Ennever JA. Anatomy of the ocular motor nuclei. In: Kennard C, Rose FC, eds. Physiological aspects of clinical neuroophthalmology. London: Chapman \& Hall, 1988:199-208.

5 Büttner-Ennever JA, Büttner U, Cohen B, et al. Vertical gaze paralysis and the rostral interstitial nucleus of the medial longitudinal fasciculus. Brain 1982;105:125-49.

6 Strassman A, Highstein SM, McRea RA. Anatomy and physiology of saccadic burst neurons in the alert squirrel monkey. I. Excitatory burst saccadic burst neurons in the alert squirre
neurons. $\mathcal{F}$ Comp Neurol 1986;249:337-57.

7 Henn V, Lang W, Hepp K, Reisine H. Experimental gaze palsies in monkeys and their relation to human pathophysiology. Brain 1984; 107:619-36.

8 Bronstein AM, Morris J, Du Boulay G, Gresty MA, Rudge P. Abnormalities of horizontal gaze. Clinical, oculographic and magnetic resonance imaging findings. I. Abducens palsy. $\mathcal{f}$ Neurol Neurosurg Psychiatry 1990;53:194-99.

9 Büttner-Ennever JA, Cohen B, Pause M, Fries W. A raphe nucleus of the pons containing omnipause neurons of the oculomotor system in the monkey. $\mathcal{A}$ Comp Neurol 1988;267:307-21.

10 Büttner-Ennever JA, Uemura T, Arai Y, Mehraein P. A possible cause for oculomotor deficits in Gaucher disease. Proceedings of the VIIIth International Neuro-Ophthalmology Symposium 1990, C019.

11 Cannon SC, Robinson DA. Loss of the neural integrator of the oculomotor system from brain stem lesions in monkey. I Neurophysiol 1987; 57:1389-409.

12 Straube A, Kurzan R, Büttner U. Differential effects of bicuculline and muscimol microinjections into the vestibular nuclei on simian eye movements. Exp Brain Res 1991;86:347-58.

13 Selhorst JB, Stark L, Ochs AL, Hoyt WF. Disorders in cerebellar ocular motor control. I. Saccadic overshoot dysmetria, an oculographic, control system and clinico-anatomical analysis. Brain 1976;99:497-508.

14 Baloh RW, Yee RD, Honrubia V. Eye movements in patients in Wallenberg's syndrome. Ann NY Acad Sci 1981;374:600-13.

15 Heywood S, Ratcliff G. Long-term oculomotor consequences of unilateral colliculectomy in man. In: Lennerstrand G, Bach-y-Rita P, eds. Basic mechanisms of ocular motility and their clinical implications. Oxford: Pergamon, 1975:561-4.

16 Pierrot-Deseilligny C, Rosa A, Masmoudi K, et al. Saccadic deficits after a unilateral lesion affecting the superior colliculus. $₹$ Neurol Neurosurg Psychiatry 1991;54:1106-9.

17 Shallo-Hoffmann J, Sendler B, Muhlendyck $H$. Normal square wave jerks in different age groups. Invest Ophthalmol Visual Sci 1990;31:1649-52.

18 Sharpe JA, Herishanu YO, White OB. Cerebral square wave jerks. Neurology 1982;32:57-62.

19 Rascol O, Sabatini U, Simonetta-Moreau M, et al. Square wave jerks in Parkinsonian syndromes. If Neurol Neurosurg Psychiatry 1991;54: 599-602.

20 Dolsac MJ, Dell'Osso LF, Daroff RB. Multiple double saccadic pulses occurring with other saccadic intrusions and oscillations. NeuroOphthalmology 1983;3:109-16.

21 Fletcher WA, Sharpe JA. Saccadic eye movement dysfunction in Alzheimer's disease. Ann Neurol 1986;20:464-71.

22 Leigh RJ, Hewman SA, Folstein SE, et al. Abnormal ocular motor control in Huntington's disease. Neurology 1983;33:1268-75.

23 Selhorst JB, Stark L, Ochs AL, Hoyt WF. Disorders in cerebellar ocular motor control. II. Macrosaccadic oscillation. An oculographic control motor control. II. Macrosaccadic oscillation. An oculograph

24 Zee DS, Robinson DA. A hypothetical explanation of saccadic oscillations. Ann Neurol 1979;5:405-14.

25 Ridley A, Kennard C, Scholtz CL, et al. Omnipause neurons in two cases of opsoclonus associated with oat cell carcinoma of the lung. Brain 1987;110:1699-709.

26 Digre K. Opsoclonus in adults: report of three cases with a review of the literature. Arch Neurol 1986;43:1165-75.

27 Ferrier D. Experiments on the brains of monkeys. Phil Trans Lond 1874; 165:433-88.

28 Tijssen CC. Conjugate deviation of the eyes in cerebral lesions. In: Daroff RB, Neetens A, eds. Neurological organisation of ocular movement. Amsterdam: Kügler-Ghedini, 1990,245-58.

29 Steiner I, Melamed E. Conjugate eye deviation after acute hemispheric stroke: delayed recovery after previous contralateral frontal lobe damstroke: delayed recovery after previc
age. Ann Neurol 1984;16:509-11.

30 Pierrot-Deseilligny C, Rivaud S, Gaymard B. Cortical control of reflexive visually guided saccades in man. Brain 1991;114:1473-85.

31 Bruce CJ, Goldberg ME. Primate frontal eye fields. I. Single neurone discharging before saccades. F Neurophysiol 1985;53:603-35.

32 Pierrot-Deseilligny C, Rivaud S, Gaymard B, Agid Y. Cortical control of memory-guided saccades in man. Exp Brain Res 1991;83:607-17.

33 Schlag J, Schlag-Rey M. Evidence for a supplementary eye field. $f$ Neurophysiol 1987;57:179-200.

34 Anderson TJ, Jenkins IH, Brooks DJ, et al. Cortical control of saccades and fixation in man; a PET study. Brain 1994 (in press).

35 O'Driscoll GA, Alpert NM, Matthysse S, et al. The neural substrates of antisaccade performance implicate oculomotor circuit dysfunction in schizophrenia. Schizophrenia Res 1994;11:149.

36 Gaymard B, Pierrot-Deseilligny C, Rivaud S. Impairment of sequences of memory-guided saccades after supplementary motor area lesions. Ann Neurol 1990;28:331-49.

37 Pierrot-Deseilligny C, Israel I, Berthoz A, et al. Role of the different frontal lobe areas in the control of the horizontal component of memory-guided saccades in man. Exp Brain Res 1993;95:166-71.

38 Guitton D, Buchtal HA, Douglas RM. Frontal lobe lesions in man cause difficulties in suppressing reflexive glances and in generating goal directed saccades. Exp Brain Res 1985;58:455-74.

39 Leichnetz GR, Goldberg ME. Higher centres concerned with eye movement and visual attention: cerebral cortex and thalamus. In: BüttnerEnnever JA, ed. Neuroanatomy of the oculomotor system. Amsterdam: Elsevier, 1988:365-430.

40 Hikosaka O, Wurtz RH. The basal ganglia. In: Wurtz RH, Goldberg ME, eds. The neurobiology of saccadic eye movements. Amsterdam: Elsevier, 1989:257-82.

41 Funahashi S, Bruce CJ, Goldman-Rakic PS. Mnemeonic coding of visual space in the monkey's dorsolateral prefontal cortex. $\mathcal{F}$ Neurophysiol 1989;61:331-49.

42 Sawaguchi T, Goldman-Rakic PS. D1 dopamine receptors in prefrontal cortex: involvement in working memory. Science 1991;251:947-50.

43 Pierrot-Deseilligny C, Rivaud S, Penet C, Rigolet HM. Latencies of visually guided saccades in unilateral hemisperic cerebral lesions. Ann Neurol 1987;21:138-48.

44 Andersen RA. Visual and eye movement functions of the posterior parietal cortex. Annu Rev Neurosci 1989;12:377-403.

45 Lasker AG, Zee DS, Hain TC, et al. Saccades in Huntington's disease: Initiation defects and distractibility. Neurology 1987;37:364-70.

46 Lasker AG, Zee DS, Hain TC, et al. Saccades in Huntington's disease: slowing and dysmetria. Neurology 1988;38:427-31.

47 Leigh RJ, Newman SA, Folstein SE, et al. Abnormal ocular motor control in Huntington's disease. Neurology 1983;33:1268-75.

48 Kennard C, Lueck CJ. Oculomotor abnormalities in diseases of the basal ganglia. Rev Neurol (Paris) 1989;145:587-95.

49 Crawford TJ, Henderson L, Kennard C. Abnormalities of nonvisuallyguided eye movements in Parkinson's disease. Brain 1989;112:1573-86. guid 0 , Clanet $M$, Montruc Parkinson's disease. Brain 1989;112:1193-214.

51 Vidailhet $M$, Rivaud S, Gouider-Khouja $N$, et al. Eye movements in parkinsonian syndromes. Ann Neurol 1994;35:420-6.

52 Crawford TJ, Goodrich S, Henderson L, Kennard C. Predictive responses in Parkinsonian's disease: manual keypresses and saccadic eye movements to regular stimulus events. $\mathcal{F}$ Neurol Neurosurg Psychiatry 1989;52:1033-42.

53 Troost BT, Daroff RB. The ocular motor defects in progressive supranuclear palsy. Ann Neurol 1977;2:397-403.

54 Pierrot-Deseilligny C, Rivaud S, Pillon B, et al. Laterally visually-guided 
saccades in progressive supranuclear palsy. Brain 1989;112:471-87.

55 Holtzman PS, Solomon CM, Levin S, Waternaux SC. Pursuit eye movement dysfunctions in schizophrenia. Arch Gen Psychiatry 1984;1 136-9.

56 Diefendorf AR, Dodge $R$. An experimental study of the ocular reactions of the insane from photographic records. Brain 1908;31:451-89.

57 Crawford TJ, Haeger B, Kennard C, Reveley MA, Henderson L Saccadic abnormalities in psychotic patients associated with neuroleptic treatment. Psychol Med (in press).

58 Nickoloff SE, Radant AD, Reichler R, Hommer DW. Smooth pursuit and saccadic eye movements and neurological soft signs in obsessive saccadic eye movements and neurological soft

59 Rapoport JL, Wise SP. Obsessive-compulsive disorder: evidence for basal ganglia dysfunction. Psychopharmacol Bull 1988;24:380-84.

60 Crawford TJ, Haeger B, Kennard C, Reveley MA, Henderson L Abnormalities of saccadic eye movements in psychotic patients. Br $f$
. Psychiatry (in press)

61 Thaker GK, Nguyen JA, Tamminga CA. Increased saccadic distractibility in tardive dyskinesia: functional evidence for subcortical GABA dysfunction. Biol Psychiatry 1989;25:49-59.
62 Fukushima J, Fukushima $\mathrm{K}$, Chiba $\mathrm{T}$, et al. Disturbances of voluntary control of saccadic eye movements in schizophrenic patients. Biol Psychiatry 1988;23:670-7.

63 Frith CD. The cognitive neuopsychology of schizophrenia. Hove: Lawrence Erlbaum Associates, 1992.

64 Kojima T, Potkin SG, Kharazmi M, et al. Limited eye movement patterns in chronic schizophrenic patients. Psychiatry Res 1989;28:307-14.

65 Tsunoda $M$, Kurachi M, Yuasa S, et al. Scanning eye movements in schizophrenic patients. Schizophrenia Res 1992;7:159-68.

66 Paus T, Petrides M, Evans AC, Meyer E. Role of the human anterior cingulate cortex in the control of oculomotor, manual, and speech response: a positron emission tomography study. $\Im$ Neurophysiol 1993; 70:453-69.

67 Glue P. The pharmacology of saccadic eye movements. $f$ Psychopharmacol Glue P. The pharma

68 Roy-Byrne PR, Cowley DS, Greenblatt DJ, et al. Reduced benzodiazepine sensitivity in panic disorder. Arch Gen Psychiatry 1990;47:534-58.

69 Tychsen L, Sitaram N. Catecholamine depletion produces irrepressible saccadic eye movements in normal humans. Ann Neurol 1989;25: 444-9.

\section{NEUROLOGICAL STAMP}

\section{Alexander Ypsilante (1792-1832)}

In 1933, Dr J E Caughey described a 54 year old woman with advanced myotonic dystrophy. ${ }^{1}$ The patient was one of eight children, five of whom had the disorder. The family lived in quite poor circumstances in Brixton, London. Her father's generation were men of a professional class. Her grandfather was a professor of Greek at a nothern university and her great grandmother was a "princess" of Greece whose brother was a "prince" and prominent statesman of a century previously. Dr Caughey found a historical document recording that the "prince" talked with a nasal voice and by age 20 was bald. This was Prince Alexander Ypsilante who was honoured on a Greek stamp in 1930. (Stanley Gibbons 435, Scott 354). The baldness is clearly shown but other features of the disorder cannot be clearly seen. The sternomastoids are covered by the tall collar. Dr Caughey's report is almost certainly the first contribution to neurological philately.

L F HAAS

1 Caughey JE. Diseases of the lens. Cataract in dystrophia myotonica. Trans Ophthalmol Soc UK 1933;53:60-70.

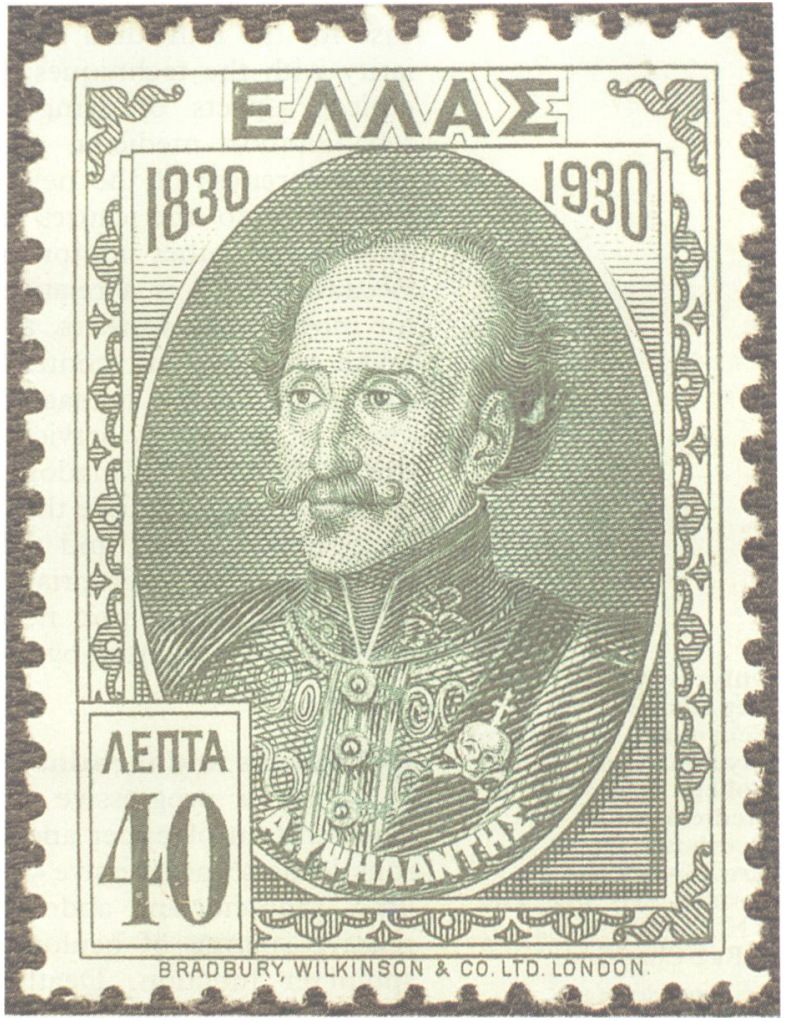

